\title{
OCTAVIO PAZ Y SU LAUREL: LECTOR DE RUBÉN DARÍO Y JUAN RAMÓN JIMÉNEZ
}

\author{
OCTAVIO PAZ AND HIS LAUREL. READER OF RUBÉN DARÍO AND \\ JUAN RAMÓN JIMÉNEZ
}

Francisco Moya Ávila

Universidad de Sevilla

\begin{abstract}
Resumen: Genios y figuras de la palabra, la sombra de Rubén Darío y Juan Ramón Jiménez se despliega a través del tiempo, extendiendo su herencia poética a lo largo de los años y las generaciones posteriores de poetas. Padre de la poesía moderna por un lado, y hacedor de su desnudez máxima por otro, ambos escritores son analizados y releidos por uno de los intelectuales más importantes que nos dejó el pasado siglo XX, Octavio Paz, a través de la antología Laurel y de dos de sus primeros ensayos.
\end{abstract}

Palabras clave: Rubén Darío, Juan Ramón, Paz, Laurel, modernismo.

Abstract: The shadow of the poetry of Rubén Darío and Juan Ramón Jiménez is spreaded over time, extending their poetic heritance throught next years and generations of poets. These intellectuals -the first, father of the modern poetry and the second, representative of his highest nude- are analyzed and read once again by one of the most important intellectual of the 20th century: Octavio Paz. We use the anthology Laurel and two of his early essays.

Keywords: Rubén Darío, Juan Ramón, Paz, Laurel, modernism.

\section{INTRODUCCIÓN}

Todos hemos vivido en alguna ocasión la experiencia de escuchar un determinado nombre y sentir cómo rápidamente en nuestra cabeza se abren miles de cajones donde guardamos la información de nuestro aprendizaje a través de los años, e, incluso, hasta percibimos cómo los filtros de nuestro cerebro van cribando dicha amalgama de recuerdos, de anotaciones mentales, para finalmente colocar sobre la mesa de nuestra conciencia aquellos documentos neuronales que reservamos sobre ese nombre que oímos. Son miles los personajes representativos que enmarcan y delimitan nuestro conocimiento socio-histórico, y en torno a los cuales erigimos diferentes concepciones en función de la trascendencia que 
hayan supuesto para el ser humano y su desarrollo político, lingüístico, cultural, etc. Rubén Darío y Juan Ramón Jiménez son, indiscutiblemente, dos identidades que generan estas reacciones cognitivas en nosotros. Máximo exponente del modernismo hispanoamericano, por un lado, y genio como poeta en cuanto a la innovación retrospectiva que supuso su interiorización de la poesía, por otro, estos dos autores canónicos, no solo de la literatura de habla española, sino de la universal, se convierten en los pilares fundamentales en los que se postula este trabajo que pretende mostrar una visión matizada mediante los filtros y consideraciones críticas de uno de los mejores lectores que nos dejó el siglo XX: el mexicano Octavio Paz. Por lo tanto, el objetivo de este trabajo es presentar la interpretación que Paz realiza sobre las influencias, aportaciones, descubrimientos y desarrollos poéticos de ambos autores, basándome sobre todo en tres ejes de rotación sobre los que dinamizar la estructura del ensayo: la Antología de la Poesía Moderna en Lengua Española Laurel, sacada a la luz por la editorial Séneca el 20 de agosto de 1941; y los ensayos "El espejo del alma"y "El corazón de la poesía”, publicados ambos en el diario mexicano Novedades, el 23 y el 30 agosto de 1943, respectivamente. No obstante, también servirán de apoyo otros textos de notable importancia como los ensayos "El caracol y la sirena" del propio Octavio Paz, y "Rubén Darío: Los placeres de luz en el abismo" de Saúl Yurkievich, recogido en su libro Celebración del modernismo.

\section{RUBÉN DARÍO Y JUAN RAMÓN EN LAUREL}

El primero de los puntos de rotación en los que se sustenta este trabajo sobre el conocimiento y estudio del mexicano en torno a las figuras de Darío y Juan Ramón será, como dije anteriormente, la Antología de Poesía Moderna en Lengua Española Laurel. Pese a ser publicada en 1941, es en 1986 -fecha de su segunda edición-, cuando Octavio Paz rememora los años en los que se fraguó la antología, junto a Xavier Villaurrutia, Emilio Prados, y Juan Gil Albert, en una advertencia realizada para dicha ocasión:

En los primeros meses de 1940 la editorial Séneca, que dirigía José Bergamín, nos encargó a Xavier Villaurrutia, Emilio Prados, Juan Gil Albert y a mí, una antología de la poesía moderna en lengua española. El libro Laurel apareció a mediados de 1941 (Antolog. Epílogo 1988a: 485)ํ.

Si bien es cierto que Paz tuvo la idea de confeccionar una antología que mostrase al público lector del momento la unión y continuidad de la poesía en lengua española, fue Villaurrutia el que dirigió, desde el primer momento, los trabajos

1 El epílogo de Octavio Paz, titulado "Laurel y la poesía moderna", aparece en la segunda edición de la antología Laurel, terminada en 1986 pero publicada por primera vez en la editorial Trillas en 1988. 
que se iban realizando. Tal fue su labor que el propio Paz que asegura que este fue el principal autor de la antología:

Xavier Villaurrutia fue, primordialmente, el autor de la antología Laurel. Yo fui su colaborador más cercano. Emilio Prados casi nunca asistía a las reuniones y su contribución se redujo a la selección de sus propios poemas. En cambio se encargó de la tipografía y la imprenta. Gil Albert estaba lleno de buena voluntad pero conocía apenas la poesía hispanoamericana. De modo que no pudo ayudarnos mucho en la selección de la obra de los poetas nacidos en América; sin embargo, colaboró con acierto y con gusto en la sección española del libro (Antolog. Epílogo 1988a: 486).

Finalmente, el libro terminó de imprimirse el 20 de agosto de 1941. Esperado con cierta expectación, provocó numerosos comentarios y reacciones, la gran mayoría venidos desde América, puesto que la España fascista, azotada por la dictadura del General Francisco Franco, vivía aislada a los acontecimientos sucedidos fuera de sus fronteras.

Desde el comienzo se postuló como un volumen al cual rodeó el escándalo y la crítica por diferentes motivos. Uno de los más llamativos e interesantes, fue el protagonizado por las figuras de Juan Ramón Jiménez, Pablo Neruda y León Felipe, al negarse a figurar en la antología a pesar de haber sido incluidos por los creadores de la misma. Una negación bastante impactante, que no se apoyaba en cuestiones estéticas o de índole ideológica, sino en razones puramente personales. Centrándome en la disputa en torno a la figura de Juan Ramón Jiménez, es importante recordar la consideración que el poeta de Moguer tenía sobre José Bergamín, colaborador de la antología en muchas de las observaciones que modificaron o perfilaron el rumbo de las selecciones de algunos poetas aparecidos en el volumen, así como en la elección del título y del epígrafe de Lope de Vega: Presa en laurel la planta fugitiva. Para Juan Ramón, Bergamín era miembro del grupo de poetas confabulados en su contra -entre los que se encontraban también Jorge Guillén y Pedro Salinas-, por lo que se negaba a aparecer dentro de la antología. Pese a que dejó claro que consideraba inocentes a los autores del volumen, el vacío que dejaba la desaparición de sus composiciones suponía un duro varapalo para el libro, por lo que la editorial Séneca interpretó el silencio del poeta a las cartas que le enviaron para que reconsiderara su postura, como una aprobación de su inclusión en el aparataje final del libro. Un acierto por parte de la editorial, puesto que finalmente Laurel fue una antología más orientada a la tradición lírica representada por Juan Ramón Jiménez, que aquella que promovían sus críticos y adversarios (Antolog. Epílogo 1988a: 487). 


\begin{abstract}
¡Qué pobre vida ésta que te doy,
Obra que no te sientes!

¡Eres tan negra como el sol, tan sola

de ti, como la tierra que te lleva! ¡Obra;

pétrea mujer desnuda, hermosa piedra mía, ciega como la brisa y las estrellas! ${ }^{2}$
\end{abstract}

Avanzando en la advertencia y en el epílogo que Octavio Paz redacta para la segunda edición de Laurel, es importante detenerse a repasar el análisis breve que realiza de cada uno de los seis primeros poetas incluidos en la primera parte de la antología. En ellos Villaurrutia encuentra el anuncio de la nueva poesía, puesto que una parte de sus obras, no se centran únicamente en los estilos y preceptos del modernismo, sino que "se abren a experiencias nuevas con singular arrojo y maestría” (Antolog. Epílogo 1988a: 492). Miguel de Unamuno, Rubén Darío, Enrique González Martínez, Leopoldo Lugones, Antonio Machado y Juan Ramón Jiménez, van más allá y anuncian por su soledad, su influencia, o su tendencia a la purificación de la expresión poética, un nuevo tiempo de la poesía española, conformando así, el grupo inicial de la lírica española en Laurel (Antolog. Prólogo 1988a: 16). En este sentido, Paz señala las figuras de Lugones y Jiménez, dentro de ese grupo, como los principales enunciadores de ciertos rasgos de la poesía surgida alrededor de 1920, aunque no los representantes puros de lo que llegará a ser ésta:

En fin, aunque en algunos de los seis poetas que forman la primera parte de Laurel, sobre todo en Lugones y en Jiménez, aparecen ya ciertos rasgos que anuncian la poesía que surge hacia 1920, ninguno de ellos puede verse como un verdadero contemporáneo de Apollinaire, Reverdy o Pound. En el sentido amplio de la palabra son modernos; no lo son en la acepción más restringida e histórica que doy al término (Antolog. Epílogo 1988a: 492).

Una vez realizada esta escueta presentación del primer grupo de poetas de Laurel, pasa a detenerse en cada uno de los que lo forman. El primero del que hablará será Rubén Darío, el cual describe literalmente como "uno de los grandes poetas de nuestra lengua", anunciando que "su poesía durará lo que dure el castellano" (Antolog. Epílogo 1988: 492). No es para menos, el nicaragüense vive y representa en sus versos las tres etapas del drama poético que acontece el paso entre siglos, que no es sino la resaca del despoblamiento atroz y despiadado del escenario literario español, que pasa de la apoteosis estética y temática de

2 La poesía de Juan Ramón se desnuda ante el poeta que la observa, como una estrella inalcanzable y solitaria cuya voz callada va calando en el interior del que la escucha. Una reivindicación de la poesía y no de los poetas que se convierte en emblema de la antología Laurel. 
los siglos de Oro, a un panorama fantasmagórico donde no hay nada (Paz 1991: 7). Siendo joven conoce la escritura de Campoamor y Bécquer -islote poético del movimiento lírico puro en España durante el siglo XIX-, cuyo verso recubre y empapa a través de las Rimas, su ánimo y experiencia. Más tarde descubre a Manuel Gutiérrez Nájera, José Asunción Silva y Julián del Casal ${ }^{3}$, precursores del movimiento modernista que dará forma en sus composiciones, haciendo realidad la promesa de una nueva estética, inconformista y renovadora, de idéntica violencia que la barroca, aunque de menor opulencia, que, finalmente, irá diluyéndose a comienzos del siglo XX (Antolog. Prólogo 1988a: 871-873). No resulta, por lo tanto, descabellado que Octavio Paz considere a Rubén Darío el poeta con el cual la poesía moderna tiene su línea de salida en lengua española. Un duro papel ser el modelo a seguir, la vanguardia de un cambio que comienza a surgir en las últimas décadas del siglo XIX, y que lo llevará a ser el motor de renovación de una transformación necesaria. Por lo tanto, "con Darío comienza la poesía moderna en español; asimismo, su obra fue un obstáculo, una frontera, que sus sucesores tuvieron que saltar, perforar o derribar" (Antolog. Epílogo 1988a: 492). Un escollo que necesitarán superar aquellos que sigan la estela de la modernidad en lengua española, habiéndose alcanzado el mediodía de la misma a través del nicaragüense. Una importancia mayúscula que se plasmó tanto en la aparición de una crítica contraria al poeta, como en la creación de grupos de jóvenes en el ambiente intelectual de la época que, motivados por los versos de Darío, decidieron alzar la voz y mostrar su apoyo al poeta a través de diferentes manifestaciones. Ejemplo de ello es el caso del discurso "El simbolismo" de Carlos Romagosa, leído en un homenaje ofrecido a Rubén Darío en 1896; o la carta de presentación que entrega a Leopoldo Lugones con el fin de ayudarle en su nueva aventura, al producirse su salida de Córdoba para conocer la vida bonaerense ${ }^{4}$ tal y como había hecho anteriormente Rubén Darío (Morales 1998: 85-87). Dirigida a Mariano de Vedia, director de la revista La Tribuna, en la cual casualmente participaba el nicaragüense, posee como cierre la siguiente alabanza:

Pero cuando quiero encantar mi espíritu; cuando quiero deleitarlo puramente, sin experimentar acerbas ni recónditas tristezas, entonces leo al divino nicaragüense Rubén Darío. Leyendo a Rubén Darío se enciende dulcemente

3 Julián del Casal es el inmediato antecesor de Darío en Hispanoamérica. Primer poeta maldito, urbano en cultivar las flores del mal, describiendo en su poesía el ambiente nocturno de las ciudades, misteriosas y pecaminosas, donde la ley queda fuera. Del Casal es el precursor de la bohemia a la parisina, y en sus composiciones predica el exotismo, las exaltaciones artísticas y los extremos eróticos (Yurkievich 1976: 37-38)

4 "En Buenos Aires, Darío descubre la pujanza de la vida moderna: la ciudad portuaria, en plena mutación de aldea a cosmópolis, comienza a equipararse a las grandes capitales, con su tráfico marítimo y su tráfico callejero, con sus fábricas humeantes, con su edificación alta y pretenciosa, con el aluvión inmigratorio (...)" (Yurkievich 1976: 28-29). 
la fantasía, sin que el corazón se oprima ni los nervios vibren dolorosamente [...] De imaginación móvil, de imaginación vivaz, de imaginación inagotable en colores, parece que la naturaleza se ha complacido en teñirle la imaginación con todos los más espléndidos tintes tropicales 5 .

En lo referido al contenido de las composiciones de este grupo de poetas, es común ver como hay una unidad de temas y recursos en este momento, definido como inconformista a través no sólo de ecos americanos sino también españoles, hallándose contrariados con su pasado poético más reciente (Antolog. Prólogo 1988: 14). Tal es así, que el modernismo tiene una doble importancia, según Paz: por una parte, recuperan la gran tradición hispánica, inmersa en los retazos constantes de una tradición de la ruptura que había detenido su avance en el siglo XVII; y por la otra, al abrirse al mundo, logran reavivar el idioma, convirtiéndose en el lenguaje de la época, incluso para aquellos opositores que involuntariamente lo homenajeaban (Paz 1991: 8).

\section{Alma mía}

Alma mía, perdura en tu idea divina, todo está bajo el signo de un destino supremo; sigue en tu rumbo, sigue hasta el ocaso extremo por el camino que hacia la Esfinge te encamina.

Corta la flor al paso, deja la dura espina; en el rio de oro lleva a compás el remo; saluda el rudo arado del rudo Triptolemo, $\mathrm{y}$ sigue como un dios que sus sueños destina...

Y sigue como un dios que la dicha estimula, y mientras la retórica del pájaro te adula, $\mathrm{y}$ los astros del cielo te acompañan, y los

ramos de la Esperanza surgen primaverales, atraviesa impertérrita por el bosque de males sin temer las serpientes; y sigue, como un dios... ${ }^{6}$

${ }^{5}$ La carta "A Mariano de Vedia", escrita en Córdoba el 16 de febrero de 1896, aparece recogida en el volumen Vibraciones fugaces de 1903.

6 El tema del alma en Rubén Darío aparece en su propia prehistoria literaria. Surge como síntoma de cualquier individualidad, revelándose como una especie de sinónimo de la subjetividad. $\mathrm{El}$ alma del poeta se contrapone al alma de la amada a la que se dirige el poema en numerosas composiciones. En esta ocasión, el yo poético se dirige al alma caminante por el caos, instándole a que siga su paso, sin hacer caso a todo aquello que rodea su camino. Como un dios, camina el poeta renovando con su obra su pasado, ese que lo nutre y el cual destruye para crear un futuro nuevo, eco de la modernidad naciente. 
Si bien Darío supone el comienzo del modernismo según el mexicano, la figura de Juan Ramón Jiménez se postula como el punto desde el cual parte la corriente central de los sucesivos movimientos que conformarán la poesía posterior. Para Octavio Paz, desde la aparición de Juan Ramón, la poesía modernista cambia, muta y se hace otra, otras, inspiradas todas ellas por una sed irrefrenable de cambio. La poesía de Jiménez, sin embargo, sirve de freno ante ciertos excesos que promulgaban las vanguardias nacientes, para así acercarlas más a su deseo de simplicidad y desnudez.

Nacida en el modernismo, la poesía de Jiménez, como él mismo lo dice en uno de sus poemas, era "una reina fastuosa de tesoros"; después, la reina comienza a desnudarse y aparece ante nuestros ojos, paulatinamente, una muchacha desnuda. Desnudez quimérica: el cuerpo real de la mujer se ha convertido en un haz de reflejos, ondas y destellos. La influencia de Jiménez fue doble: fue un freno ante las desmesuras de la vanguardia y, al mismo tiempo, desvió sus ímpetus y diluyó sus poderes de subversión creadora (Antolog. Epílogo 1988a: 494).

Este proceso evolutivo que experimenta la poesía de Juan Ramón culmina finalmente con Espacio. Como indica el propio Paz, el poema con Jiménez "pierde cuerpo y forma hasta reducirse a una suerte de exhalación lírica, entre el silencio y el habla” (Antolog. Epílogo 1988a: 494).

En la evolución de Juan Ramón se advierte una gradual y cada vez más profunda asimilación de lo mejor de la vanguardia [...] Al desprenderse de los ropajes modernistas, la búsqueda de la extrema simplicidad lo conduce a una poesía más cerca de la exclamación que de la metáfora, más flor que raíz (Antolog. Epílogo 1988a: 494).

Sensaciones y emociones copan de lleno su poesía centrada en el instante como unidad de tiempo efímero, mientras se deshace lentamente en la inmensidad de sus versos breves pero suficientes. De esta forma, "la estética de Juan Ramón es impresionista: no lo que ven los ojos sino la sensación que experimentan” (Antolog. Epílogo 1988a: 494).

\section{Cénit}

Yo no seré yo, muerte, hasta que tú te unas con mi vida y me completes así todo; hasta que mi mitad de luz se cierre con mi mitad de sombra,

$-y$ sea yo equilibrio eterno en la mente del mundo: 
unas veces, mi medio yo, radiante;

otras, mi otro medio yo, en olvido. -

Yo no seré yo, muerte,

hasta que tú, en tu turno, vistas

de huesos pálidos mi alma. ${ }^{7}$

\section{NOVEDADES Y DOS ENSAYOS SOBRE POESÍA}

Muchos fueron los ensayos publicados por Octavio Paz en el diario mexicano Novedades, durante la década de los cuarenta dentro de la iniciativa cultural del suplemento México en la cultura que promovió el editor Fernando Benítez desde el año 1946, y que llegó a alcanzar la estimable cifra de 665 publicaciones. En este proyecto colaboraron grandes intelectuales del momento. Por citar alguno de ellos, podemos encontrar en sus páginas a Vicente Rojo, Juan Rulfo, José Emilio Pacheco, Luis Cernuda, Gabriel García Márquez, Rosario Castellanos o Cristina Pacheco.

Ya en la nota editorial de la primera edición del suplemento, el 6 de febrero de 1946, Fernando Benítez aclara cuál es la finalidad de esta nueva iniciativa de Novedades:

Novedades, con la colaboración de los más grandes artistas, hombres de ciencia y periodistas de México, presenta hoy su nuevo suplemento. Este nuevo esfuerzo permitirá a nuestro diario igualar, con una característica propia y un espíritu esencialmente mexicano, lo que en ese aspecto de la prensa moderna más prestigiada del mundo es ya un servicio insustituible. [...] Abrimos una ventana al paisaje entrañable de México, al de su cultura, que es en nuestros días conturbados un motivo de orgullo y una lección de callado heroísmo. Lo mexicano con trascendencia universal y lo universal que fecunde lo mexicano podría servir como un lema. [....] Las ideas, las artes y las ciencias, puestas al alcance de todos. Instruir deleitando es asimismo una de las finalidades, y no la menor, de la prensa moderna. ${ }^{8}$

Siendo un emplazamiento idóneo para la promoción de la cultura, Octavio Paz publica en las páginas de este diario los ensayos restantes que funcionan como ejes para este trabajo sobre la faceta lectora y crítica del mexicano, centrada

7 Juan Ramón hace en este poema una comparación entre la existencia y la nada, la ausencia y la presencia. El ser humano vive impregnado por la persistente sensación de estar en una procesión imparable hacia la fusión del cuerpo con las sombras, formando el equilibrio perfecto entre luz y oscuridad. Es la muerte, fin común del ser vivo, aquel en el que podremos ser nosotros mismos, abrazados a la otra mitad de nuestro yo inaccesible hasta el momento, pero presente en el decadente contexto que nos rodea.

${ }^{8}$ Esta es la nota editorial del primer número del suplemento "México en la Cultura", redactada por Fernando Benítez y publicada en Novedades el 6 de febrero de 1946. 
en las figuras de Rubén Darío y Juan Ramón. Son publicados en 1943 bajo el título de "El espejo del alma" y "El corazón de la poesía", respectivamente.

Precisamente el primero de ellos, "El espejo del alma", comienza haciendo referencia a la antología Laurel, y a la necesidad imperante que el mexicano siente de reflexionar sobre su publicación, su recepción, y la finalidad real por la que se confeccionó.

Releer Laurel, Antología de la poesía moderna en lengua española, puede parecer en estos tiempos tarea vana, cuando no pecado contra las consignas de ciertos sultanes de la poesía. [...] Es inútil enumerar todos los equívocos que lo oscurecen y es inútil también describir cómo se han cebado en sus páginas las malas pasiones, guiadas por la hipocresía, que las ha disfrazado con mil virtuosos ropajes. Pero, más allá de sus limitaciones y de sus generosidades, este libro tenía un objeto que los críticos de bajo vuelo no han querido ver: mostrar la comunidad de la palabra poética de América y España (Paz 1988b: 349).

A lo largo del ensayo, podemos observar cómo el mexicano realiza una defensa de la utilidad e importancia que posee el volumen que, junto a Villaurrutia, Gil Albert, y Prados, confeccionó en 1941. No es una simple antología, con Laurel se presenta al ser vivo que es en realidad la poesía, la cual aquejada del maltrato continuo de una crítica centrada más en la superficialidad de las letras, del papel, o de un nombre, ha permanecido oculta bajo insensibilidad de aquellos que la nombran sin cesar. Es necesario oír su respiración, el lenguaje universal que nos ofrece para comprender al mundo, y de paso observar el testimonio que se nos ha legado a través del tiempo. Sin duda, "El espejo del alma" no se trata de un ensayo sobre poetas, sino sobre la poesía, verdadera protagonista para Paz en el duro debate sobre el acierto o no del volumen Laurel. Sirve, por tanto, para mostrar que la poesía hispanoamericana no está tan difuminada de su cauce original y propio, a pesar de sus diferentes redes de canales confundidos y entrelazados. Se resisten los versos, que en sus páginas se muestran, a ser vistos únicamente como espejos de nombres, es decir, como simples listados con un pequeño garabato encima que los identifique. Prefieren ser, en todo caso, un espejo subyacente que refleje con la luz cegadora del mediodía absorto el alma poética del mundo. La poesía sobrevive y se muestra tajante ante ello, ya que como bien dice Paz: "Esta favorable resistencia es toda nuestra tradición poética" (Paz 1988b: 351). Una tradición poética en la que se encuentran incluidos para el mexicano tanto Rubén Darío, como Juan Ramón Jiménez.

Pero entonces, si la poesía moderna es un ser vivo, ¿¿dónde está su corazón? Octavio Paz consciente de esta duda escribe para intentar responderla, el último eje sobre el cual sustento este trabajo: el ensayo "El corazón de la poesía".

Si bien la resistencia se presupone como tradición poética, también debe serlo la ruptura de ésta. La poesía moderna, sobre la cual se compone la antología poética Laurel, se sustenta como una ruptura del orden tradicional. 
Precisamente por este motivo, a riesgo de parecer un oxímoron, se consolida como un continuum de las líneas más constantes y profundas de esta tradición negada en primer plano. En muchos de los autores que en ella aparecen, pueden verse claros ritmos y formas de poetas anteriores. Paz señala algunos como Alberti, a través del cual se aprecia la herencia de Gil Vicente, Góngora, Pedro de Espinosa, o de los propios Juan Ramón y Darío. Sin embargo, pese a ser una antología de poesía moderna, los poetas modernistas no aparecen reflejados en sus páginas. En cambio, sí lo hacen aquellos que sobrepasaron sus límites, como si de un punto de partida se tratase sobre el cual impulsarse hacia una evolución de la poesía mucho más vivaz y con un espíritu renovado. Este es el caso de Rubén Darío -y posteriormente Juan Ramón Jiménez-, dos poetas que devolvieron la vida a una poesía que estaba sufriendo una decadente caída hacia la monotonía modernista.

Si la función del modernismo americano consistió en recordarle a España su perdida universalidad, fertilizando su casticismo romántico y naturalista, la obra de Darío -y después la de Juan Ramón- posee un sentido semejante: devolverle a la poesía su movimiento y su vivacidad, su espíritu, petrificado en esa deslumbrante parálisis en que culmina el modernismo (Paz 1988c: 352).

Tal fue la importancia del nicaragüense para Octavio Paz,que según élla poesía moderna comienza a través de sus versos. Criticado por su afrancesamiento por unos; y por su europeísmo por otros, Rubén Darío demostró que el casticismo español no era más que el romanticismo y naturalismo francés convertidos en una costumbre; y la necesidad imperante de América en utilizar a Europa como línea de salida desde la que partir para lograr rencontrarse a sí misma.

El "casticismo español" no era más que el romanticismo y naturalismo franceses convertidos en hábito, en "costumbrismo". Los críticos americanos de Darío, por su parte, parecían ignorar que nuestro continente es una creación de Europa, en un sentido literal. Esto es, que América, si se quiere encontrar a sí misma, debe partir de Europa, porque sólo la cultura europea posee formas capaces de resistir, sin romperse, todos los ingredientes nativos (Paz 1988c: 352-353).

Para Rubén Darío el espíritu europeo no es grande tan sólo por aquello que ha conseguido, por todo cuanto ha logrado aunar, sino también por esa capacidad autocrítica que le ha ido permitiendo separar, alejar y, en ocasiones, olvidar, lo vivo y lo muerto, poseyendo sus formas y destruyéndolas hasta tal punto, que el propio hombre se liberase del peso de los siglos que tras él caminaban. Por este motivo, para Octavio $\mathrm{Paz}$ el poeta nicaragüense no sólo es el inventor del modernismo, "sino, por encima de todo, el padre de la poesía moderna en español” (Paz 1988c: 353). Se convierte así en el corazón de la 
poesía; ese del cual emanará la sangre poética que inspirará a sus sucesores en el tiempo. Una poesía viva, total, donde quepa tanto la tradición como la novedad de ese futuro hecho profecía en unos cantos de vida y esperanza que nutran de espíritu nuestro ánimo.

\section{Nocturno}

Quiero expresar mi angustia en versos que abolida dirán mi juventud de rosas y de ensueños, y la desfloración amarga de mi vida por un vasto dolor y cuidados pequeños.

Y el viaje de un vago Oriente por entrevistos barcos, y el gramo de oraciones que floreció en blasfemia, $\mathrm{y}$ los azoramientos del cisne entre los charcos y el falso azul nocturno de inquerida bohemia.

Lejano clavicordio que en silencio y olvido no diste nunca al sueño la sublime sonata, huérfano esquife, árbol insigne, oscuro nido que suavizó la noche de dulzura de plata...

Esperanza olorosa a hierbas frescas, trino del ruiseñor primaveral y matinal, azucena tronchada por un fatal destino, rebusca de la dicha, persecución del mal... $\mathrm{El}$ ánfora funesta del divino veneno que ha de hacer por la vida la tortura interior, la conciencia espantable de nuestro humano cieno y el horror de sentirse pasajero, el horror

de ir a tientas, en intermitentes espantos, hacia lo inevitable, desconocido y la pesadilla brutal de este dormir de llantos de la cual no hay más que Ella que nos despertará. ${ }^{9}$

Es cierto, por otro lado, que Juan Ramón Jiménez alcanzó con sus dedos un mayor espacio, en lo que a lo poético se refiere, hasta el punto, como dice Paz, de "rozar con dedos de viento a la Poesía en su última desnudez" (Paz 1988c:

9 En la obra de Rubén Darío podemos encontrar hasta tres poemas titulados "Nocturno". Este en concreto es el primero de ellos, publicado en Cantos de vida y esperanza (1905). A través de sus versos se refleja la amarga melancolía que nace de la reflexión interna durante una noche de insomnio, en la que el dolor de la experiencia de vivir se manifiesta en la voz del poeta. 
353). Sin embargo, es Rubén Darío quien concentra y aúna en sus versos toda la poesía anterior y futura, como ese corazón que necesita la poesía para bombear su sangre a través de su incesante tradición de rupturas.

Unos son la piedra, otros el cielo, el viento, el fuego; él es el mar. Su corazón es una caracola y en ella, junto al latido de su corazón, oímos el flujo y reflujo, infinitos del mar, el latido inagotable de las aguas primeras, origen de la vida. Esa caracola es un testimonio de nuestro nacimiento y en ella están inscritos los signos de nuestro destino (Paz 1988c: 354).

\section{CONCLUSIONES}

Una vez realizado el repaso de los tres ejes sobre los que se apoya el trabajo, las conclusiones que podemos obtener son, en primer lugar, la enorme importancia que poseen dentro de la concepción histórica y poética las figuras de Rubén Darío y de Juan Ramón Jiménez, así como la enorme consideración que mantiene hacia ellos Octavio Paz, no sólo como crítico, sino también como lector. Todo esto puede verse reflejado en su aparición en una de las antologías más conflictivas y renovadoras de la primera mitad del siglo XX, de la cual hemos conocido algunos de los entresijos que la formaron gracias al epílogo que el propio Paz redactó para su segunda edición en 1986.

Por otro lado, a través de este trabajo también hemos descubierto la importancia que supuso en el mundo intelectual del siglo XX el desarrollo del suplemento "México en la cultura" del diario mexicano Novedades, en el cual, además, aparecieron publicados dos de los ensayos capitales de las Primeras letras de Octavio Paz. "El espejo del alma" y "El corazón de la poesía" nos sirven como testimonios vivos de la necesidad tangible que hubo, durante el cambio de siglo, de considerar como real la resistencia de la propia poesía a ser encasillada en nombres e ideologías, en lugar de viajar libre a través de los versos de sus poetas. Además, nos permite conocer la consideración que el propio Octavio Paz, crítico, poeta y lector, tenía tanto de Rubén Darío, al cual considera como "corazón de la poesía" que bombeará la sangre de todos aquellos que continúen a través de la estela del mundo poético; como de Juan Ramón Jiménez, capaz de rozar a la poesía con sus dedos de versos en su última desnudez y simpleza. 


\section{BIBLIOGRAFÍA}

García, Alfonso (1998): "Construyendo el modernismo hispanoamericano: Rubén Darío y Carlos Romagosa”, en: Estudios en el Centenario de Los Raros y Prosas profanas. Sevilla: Secretariado de publicaciones de la Universidad de Sevilla, 85-87.

PAz, Octavio (1988b): "El espejo del alma”, en: Primeros letras (1931-1943). Barcelona: Seix Barral, 349-351.

PAz, Octavio (1988c): "El corazón de la poesía", en: Primeras letras (1931-1943). Barcelona: Seix Barral, 352-354.

PAz, Octavio (1991): "El caracol y la sirena", en: Cuadrivio. Barcelona: Biblioteca de Bolsillo, 7-44.

Romagosa, Carlos (1903): “Carta a Mariano de Vedia”, en: Vibraciones fugaces. Córdoba: Argentina, s.e., 32-35.

YUR Kievich, Saúl ( I 976): “Rubén Darío: los placeres de luz en el abismo”, en: Celebración del modernismo. Barcelona: Tusquets Editor, 25-48.

\section{Fuentes documentales}

Laurel: Antología de la poesía moderna en lengua española/ Prólogo de Xavier Villaurrutia; epílogo de Octavio Paz. México DF: Trillas, 1988a. 
